\title{
Unmanned Aerial Vehicle for Transmission Line Inspection: Status, Standardization, and Perspectives
}

\author{
Xin Li, Zijian Li, Haizhi Wang and Wanlin Li* \\ Law School, Kunming University of Science and Technology, Kunming, China
}

OPEN ACCESS

Edited by:

Xiaoshun Zhang,

Shantou University, China

Reviewed by:

Borong Deng,

South China University of Technology,

China

Zilin $\mathrm{Li}$,

Hong Kong Polytechnic University,

SAR China

*Correspondence:

Wanlin Li

karen_lee_Ix@126.com

Specialty section:

This article was submitted to

Smart Grids,

a section of the journal

Frontiers in Energy Research

Received: 23 May 2021

Accepted: 11 June 2021

Published: 07 July 2021

Citation:

Li X, Li Z, Wang H and Li W (2021) Unmanned Aerial Vehicle for Transmission Line Inspection: Status,

Standardization, and Perspectives.

Front. Energy Res. 9:713634.

doi: 10.3389/fenrg.2021.713634
As the biggest country in power consumption and generation, China owns the largest scale of transmission line worldwide. The application of unmanned aerial vehicle (UAV) in inspection has been carried out for many years in China because of its strong adaptability and safety compared to the traditional manual way. For the further development of UAV application technology in transmission line inspection, China has accumulated rich experiences and greatly improved line inspection efficiency and formed a relatively complete UAV transmission line inspection standardization system including operation safety management, an equipment configuration method, and functional quality requirements. However, there still exist some obstacles that need to be tackled due to the fact that China's UAV transmission line inspection standardization and its international promotion have not been thoroughly and comprehensively studied at present. Based on an in-depth analysis of China's current UAV transmission line inspection standardization system, this study employs SWOT-PEST analysis to insightfully investigate international promotion opportunities/challenges under the current situation, upon which several constructive suggestions are proposed from four aspects of politics, economy, society, and technology. The ultimate purpose is to design feasible schemes to boost the international promotion of China's UAV transmission line inspection standardization and further development of international UAV inspection technology.

Keywords: UAV, transmission line inspection, standardization, promotion, SWOT analysis

\section{INTRODUCTION}

As the traditional method of transmission line inspection (Liu et al., 2019a), manual inspection has some obvious disadvantages (Muniappan, 2021) when it comes to special terrain and meteorological conditions which frequently lead to low inspection efficiency (Padhy and Panda, 2021), and personnel safety is not always guaranteed (Kumar et al., 2021). Although the United States and European countries started to use helicopters to inspect transmission lines from the middle of the 20th century, the high risk and inefficiency of manual ways have not been fundamentally addressed (FU et al., 2017). With the development of UAV application technology, UAV inspection shows its irreplaceable advantages of safety and efficiency in transmission line inspection (Kumar Injeti and Kumar Thunuguntla, 2020; Miao et al., 2020), and it has little impact on transmission lines because it can undertake on-line inspection ( $\mathrm{He}$ et al., 2020; Liang et al., 2020).

At present, research on UAV inspection tends to focus on technologies including defect monitoring, autonomous inspection, and so forth, which can be summarized as follows: 
- Research on transmission line detection technology includes the use of deep learning target identification and navigation technology, which can effectively improve the monitoring ability and reduce the inspection cost (Gangolu and Sarangi, 2020; Sui and Ning, 2021)

- The endurance of line inspection UAV is based on the flight battery optimization, UAV nest and power supply, UAV radio power transmission technology, etc. (ZHAO et al., 2017)

- Autonomous line patrol of UAV includes intelligent image data processing and autonomous intelligent line inspection, as well as the ultimate goal of the complete autonomous inspection (Tavakoli and Nafar, 2020)

This study initially investigates the characteristics of line inspection UAV and concludes that different UAV types correspond to different line inspection tasks. The development status of UAV line inspection technology is analyzed combined with the current application situation of other countries. Then, this work deeply studies China's UAV line inspection standardization system, which aims to find the international promotion path of China's UAV inspection standardization through SWOT-PEST analysis. The points are summarized as follows:

- Relying on the advantages of UAV technology, China's UAV line inspection technology is widely used and has rich experience in line inspection, which can provide efficient line inspection solutions for other countries.

- China's UAV line inspection standard has a relatively perfect system, which can provide a valuable reference for other countries to use UAV line inspection.

- Strengths-weaknesses-opportunities-threats

(SWOT) analysis and political-economical-social-technological (PEST) analysis are adopted to illustrate the strengths and weaknesses of international promotion, which also discuss the opportunities and challenges.

- The promotion of China's UAV line inspection standard may be limited by laws and regulations, but it can be changed according to the actual situation to adapt to the specific situation of corresponding countries. Generally, it has strong practicability for its promotion in the world.

\section{OVERVIEW OF UAV}

UAV refers to the unmanned aircraft operated by radio remote control equipment and a self-contained program control device or operated by using an onboard computer completely or intermittently (ICAO'scircularUAS, 2011). UAV was introduced for military investigation and attack in 1920s, as shown in Figure 1. Nowadays, it has been widely used in the civil fields including photography, security, inspection, and other industries where manual work cannot be accomplished easily. With the development of UAV technology, the range of its utilization will be much wider.

\section{Classification of UAVs}

UAV can be classified into different types according to its utilization, size, flight platform, and flight range, as shown in Figure 2 (Hassanalian and Abdelkefi, 2017). Among them, flight platform of UAV is the most significant factor to the line inspection since it considerably affects the specific application of UAV. Moreover, different characteristics of flight platforms more or less affect the mode of line patrol. Therefore, investigation of different platforms of UAV is critical to optimize the line inspection method. Next, the classification of UAV is discussed from several main aspects of the flight platform.

- Fixed-Wing UAV. Fixed-wing UAVs are larger than rotarywing UAVs under the same specifications and are more complex in taking off and landing. The fixed-wing UAV has faster speed, longer endurance, and higher flight altitude than the rotary-wing UAV (Yi et al., 2017). Fixed-wing UAVs can be used in various environments, including jungle, desert, city, ocean, and mountain areas, as shown in Figure 3A.

- Rotary-Wing UAV. Based on the rotor blade or propeller system, the rotary-wing UAVs is a smaller-size and higherpayload UAV. It has the flexibility and ability to hover in the air and go to places where fixed-wing UAVs cannot go. The rotary-wing UAV is also the cheapest compared with other types of UAV. However, its disadvantages include low endurance, instability in the wind, and limitation of flight range and altitude (Tang et al., 2018a), as shown in Figure 3B.

- Flapping-Wing UAV. Flapping-wing UAVs are based on bionics, and most of them have flexible and light wings which are important for their aerodynamic proficiency and flight stability (Chen et al., 2020), as shown in Figure 3C. Moreover, the flapping-wing UAV has strong adaptive wind resistance, but it is not widely used in the civil UAV field.

- Unmanned Airship. As an aircraft based on the principle of buoyancy, it has the fundamental characteristics of long dead time, heavy load, and stable flight, as shown in Figure 3D. It takes advantage of the lower stratospheric wind speed and other favorable conditions, carries the mission load, and lifts off by buoyancy, so as to realize the stable residence and controllable flight in the specific area (Fei, 2019). The technological development of unmanned airships varies from country to country, so it has not been popularized.

- Parafoil UAV. The parafoil UAV takes off using a powered parachute instead of wings or propellers, as shown in Figure 3E. It has the characteristics of strong endurance, vulgarity, low altitude, and stable flight (Guo et al., 2017). Also, it can be used in agriculture and forestry, aerial photography, aerial survey, weather modification operation, rescue, and relief.

\section{Application of UAV}

Nowadays, UAV has been widely used in various areas corresponding to its different characteristics (Tang et al., 2018b). Applications of UAV are listed in Table $\mathbf{1}$. 


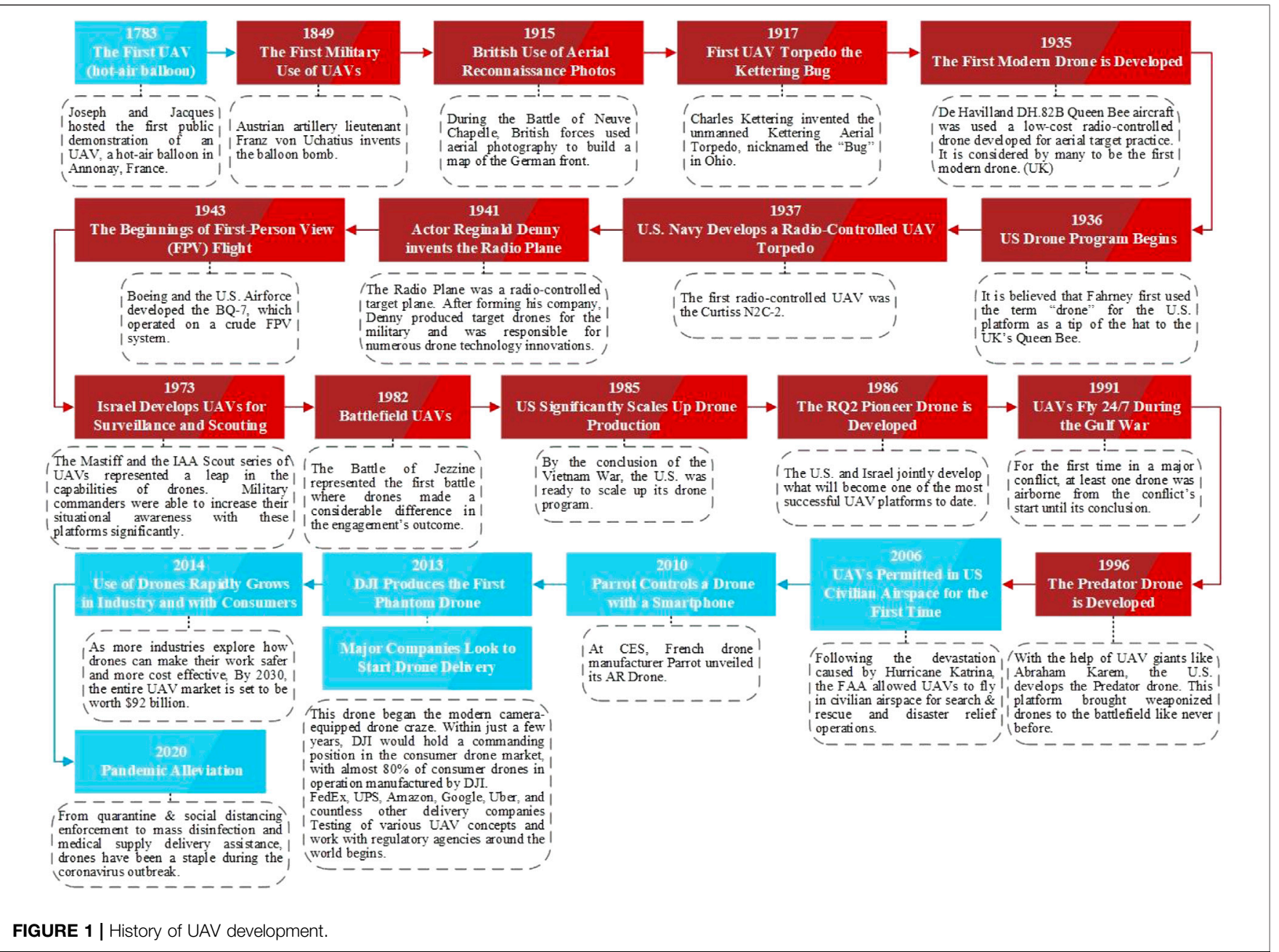

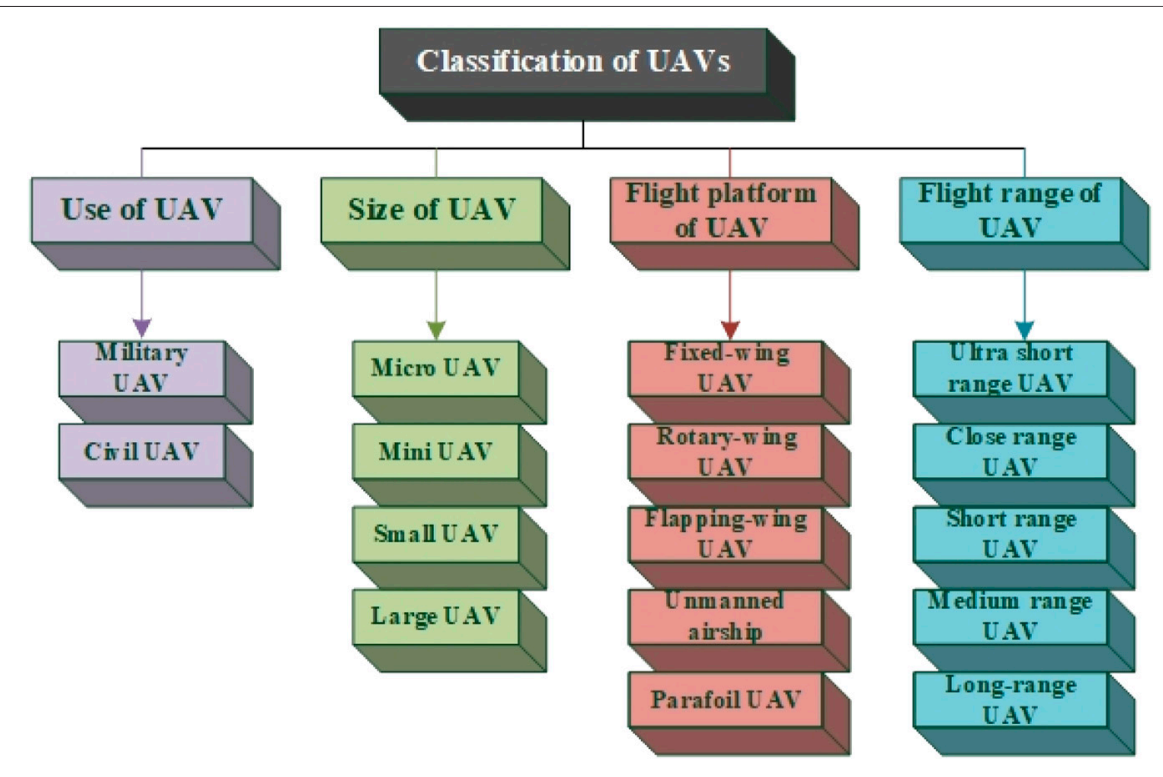

FIGURE 2 | Classification of UAVs. 


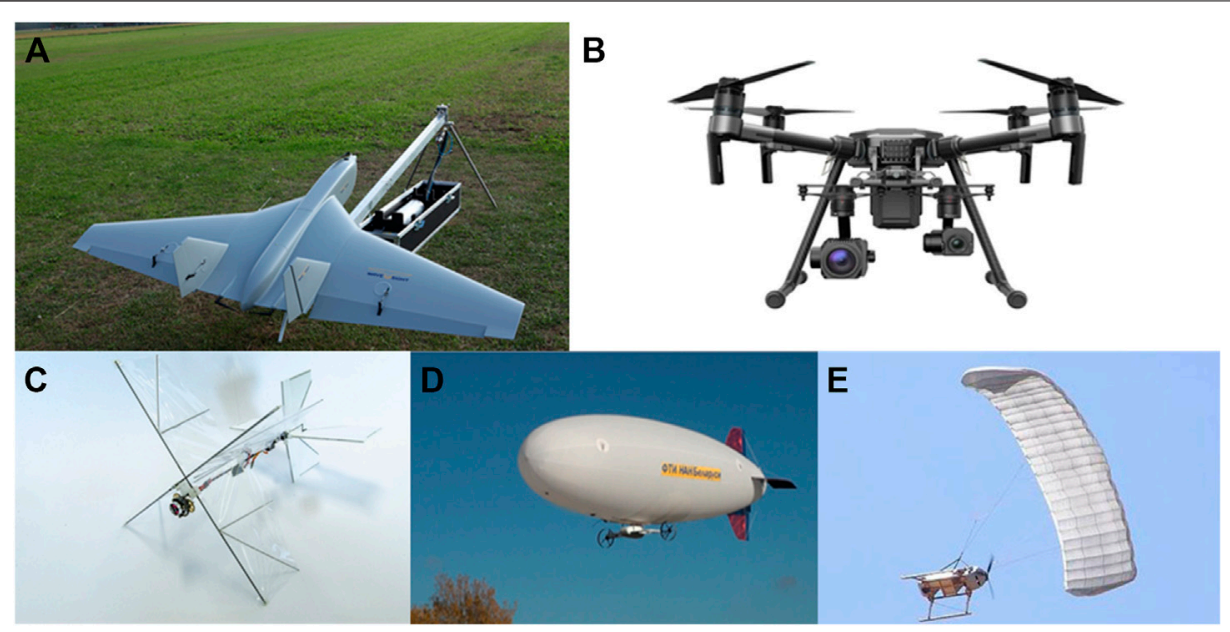

FIGURE 3 | Different types of UAVs: (A) fixed wing (Volt Aerial Robotics, 2016), (B) rotary wing (Geospatial Media and Communications, 2018), (C) flapping wing (Tzu-ti, 2020), (D) unmanned airship (Unmanned airship, 2014), and (E) parafoil UAV (Lanny Lin, 2021).

TABLE 1 | Application of UAV.

\section{Application}

fields

Aerial photography

Security

Inspection

Others
Applicable UAV

Rotary-wing UAV

Rotary-wing UAV

Rotary-wing UAV, fixedwing UAV

Rotary-wing UAV, fixedwing UAV
Characteristics of demand

Easy to operate, good image transmission effect

Long endurance, strong adaptability to harsh environment, good image transmission effect

Long endurance, strong adaptability to harsh environment, good image transmission effect, stable signal, strong load capacity, easy maintenance

Long endurance, strong load capacity, strong anti-interference ability
- Aerial Photography. UAV can carry high-definition cameras with small volumes. Using the unique perspective of the air to record sports events, performing arts activities, and film and television shooting improves the efficiency and quality of shooting (Guo et al., 2017).

- Security. UAV has been more widely used in security, such as forest fire early warning, public security prevention and control, UAV security inspection, and monitoring (Volt Aerial Robotics, 2016), which can effectively supplement and strengthen the traditional security methods.

- Inspection. UAV inspection improves efficiency via the combination of visible light, thermal infrared, and lidar image fusion technology (Geospatial Media and Communications, 2018), as well as reduces the occurrence of safety accidents.

- Others. By improving the accuracy of mapping, UAV plays an important role in the protection of cultural relics, urban planning and water conservancy monitoring, and other applications (Unmanned airship, 2014).

\section{APPLICATION OF UAV IN TRANSMISSION LINE INSPECTION}

Economic development relies on the construction of power grid. Transmission lines are getting longer and more complex in many countries. In 2009, China's power grid length of more than $200 \mathrm{kV}$ reached $375,000 \mathrm{~km}$, which surpassed the United States and ranked first in the world. By 2018, the length of the grid over $35 \mathrm{kV}$ reached 1,892,000 km. Failure or loss of power may bring direct economic losses and personnel casualty. Hence, the task of transmission line detection and maintenance is of great significance. However, due to high cost, inefficiency, and high safety risk, traditional methods for manual line inspection have many drawbacks in operation, which cannot meet the needs today. UAV inspection can make up for the deficiency of manual way and become the mainstream tool of the future of line inspection (Singhal et al., 2018).

\section{Manual Vs. Unmanned Aerial Vehicle Transmission Line Inspection}

The transmission line inspection task involves mapping and inspection of transmission line components, vegetation encroachment monitoring, icing detection and measurement, and disaster monitoring. Manual and UAV line inspection have their own advantages and disadvantages, respectively.

Manual line inspection has the disadvantages of large labor, long inspection cycle, and low efficiency. Since a lot of lines are located in the suburbs or even depopulated zones, manual line inspection requires a long trip to get there, and due to the height 


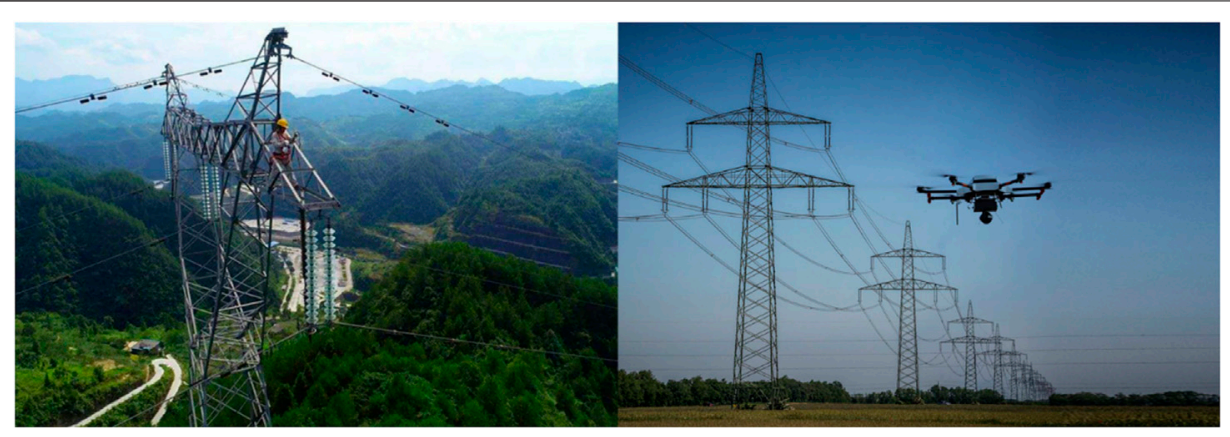

FIGURE 4 | Manual transmission line inspection and UAV inspection (Manual transmission line Inspection, 2018) (UAV transmission line Inspection, 2020).

TABLE 2 | Comparison between manual line inspection and UAV line inspection.

Line inspection mode

Manual transmission line

inspection

Advantage

Disadvantage
1. Can work in a severe weather environment

2. Maintenance at the same time

3. Low cost of manual training

1. Time consuming and inefficient

2. High safety risk
UAV transmission line inspection

1. High efficiency

2. Low cost of equipment

3. Ensure personnel safety

4. Live working

1. Restricted by harsh climate

2. High cost of training of the power tower (the general tower is $30-50 \mathrm{~m}$ high and the ultra-high voltage tower is $100 \mathrm{~m}$ high), technicians need to climb up and inspect the defects under live working, as shown in Figure 4. However, manual inspection can operate in extremely low temperature and high-altitude areas when most UAVs cannot operate normally. In addition, manual line inspection can repair the equipment in the process of line inspection, but UAV cannot yet (Peng et al., 2016).

Compared with manual inspection, UAV has lower equipment cost and higher line inspection efficiency. In the process of line inspection, UAVs can not only ensure the safety of personnel but also ensure the normal operation of transmission lines because they can do the living work. With the development of technology, UAVs may operate more complex inspection with even simple maintenance. Therefore, UAV inspection has high performance and application potential (Liu et al., 2019a). Comparisons between manual line inspection and UAV line inspection are listed in Table 2.

\section{Current Status of Unmanned Aerial Vehicle Transmission Line Inspection}

With the development of UAV and airborne sensor technology, multisensor cooperation can be realized, which improves the accuracy and automation of equipment defect judgment. Through UAV equipped with some infrared, ultraviolet, camera, and other equipment, hidden trouble in the budding state can be located and found in time, and the fault can be eliminated to protect the safe operation of the transmission line
(Hu et al., 2018). Then, the abnormal point of transmission line fault is inquired by the equipment carried, and then, the fault point is photographed in hover to obtain more obvious information, which is prepared for subsequent image processing and decision making.

According to the different working principles, the imaging loads applied in UAV inspection can be divided into three categories, namely, a visible imaging load, an infrared imaging load, and an ultraviolet imaging load, as shown in Figure 5. Infrared imaging load is mainly used for accurate and efficient detection and identification of abnormal heating defects of power transmission equipment in the process of power operation. The visible and infrared image fusion process is shown in Figure 6. Ultraviolet imaging technology is a kind of inspection technology for abnormal corona discharge and surface local pollution of transmission equipment.

Airborne lidar technology is the most representative technology for detecting the safe distance between line and ground objects. It can obtain reliable and accurate threedimensional topography and feature information of the corridor, mainly including power towers, green trees, and tall buildings.

However, UAV line inspection technology has not been widely used in the world until now. From the early 20th century, some developed countries carried out UAV line inspection on transmission lines, including routine inspection, live maintenance, and other aspects. Nowadays, China's UAV application in transmission line inspection is at the top of the world. 


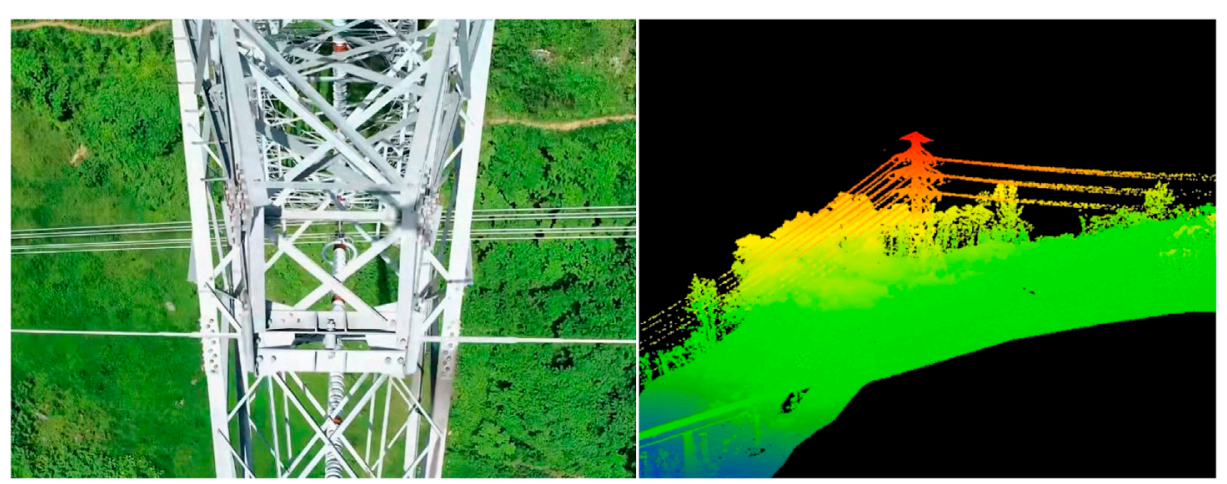

FIGURE 5 | Visible and infrared images.

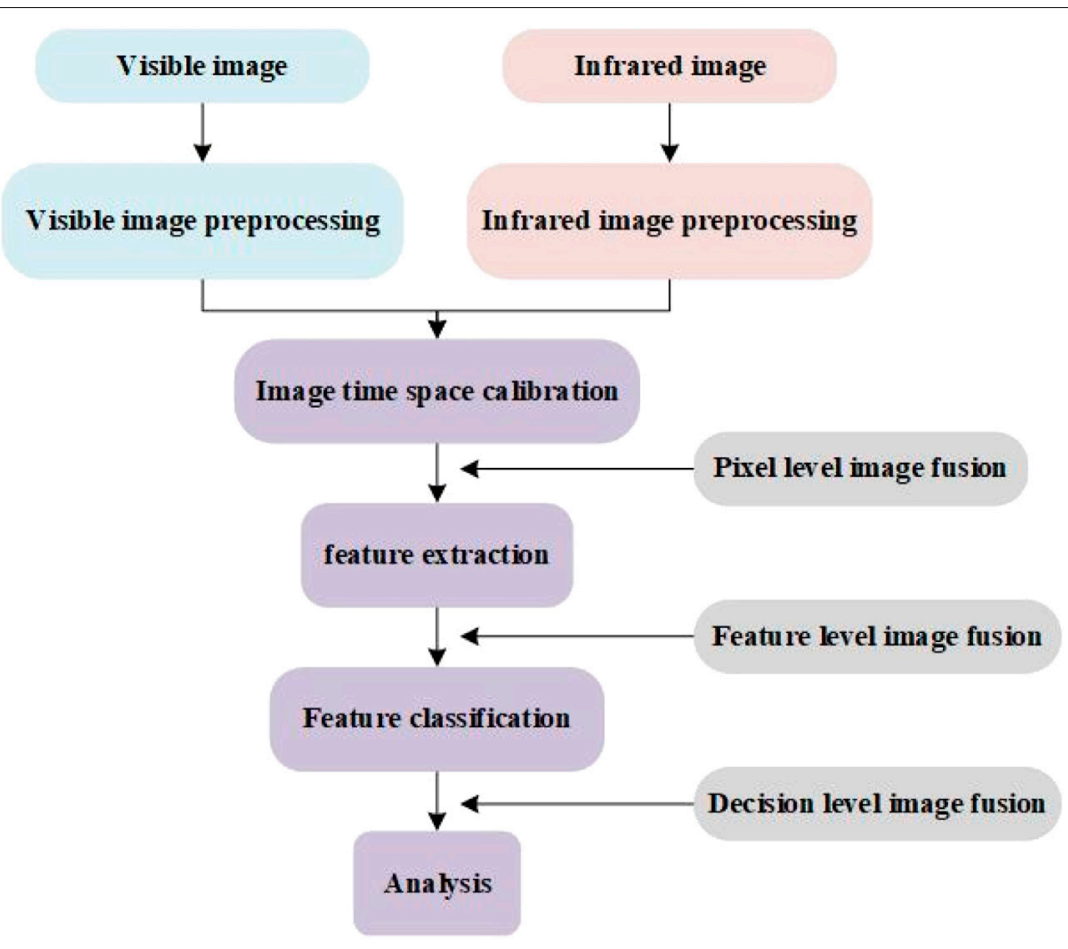

FIGURE 6 | Visible and infrared image fusion process.

\section{Current Status of Unmanned Aerial Vehicle Transmission Line Inspection in China}

From around 2010, China's electric companies have made achievements in UAV inspection and taken corresponding measures to promote the development of UAV application in line inspection. The Shandong Electric Power Research Institute and Luneng Company have jointly developed an unmanned helicopter for transmission line inspection with a high load, high-definition, and wide-angle camera; Shanghai Electric Power Company has used a small, fixed-wing UAV for transmission line inspection, which can detect high-voltage transmission lines in real-time. The State Grid also actively promotes the UAV line inspection work, sets up a UAV training center, conducts UAV flight technology training for power inspectors, and urges the formation of a UAV inspection team (Zhai et al., 2018).

In 2013, the China Southern Power Grid Corporation promoted the intelligent inspection mode of "machine inspection and manual inspection" for transmission lines and has fully realized the collaborative inspection mode of "machine inspection as the main and manual inspection as the auxiliary." In 2016, the large-scale unmanned helicopter line inspection system independently developed by Guangdong Power Grid Company was applied to electric power inspection. The UAV was equipped 
with a visible light camera, infrared thermal imager, ultraviolet imager, 3D lidar, and other sensors and realized real-time analysis and processing of inspection data (Qian et al., 2016). After 2019, Guangdong Power Grid established the first formal UAV patrol management center in China, which has mastered technical difficulties such as night patrol, radar positioning, laser point cloud data splicing, and laser automatic modeling. UAV has been widely used in power inspection, with an annual operation volume of more than 210,000 times, accounting for $87.5 \%$ of the patrol work, ranking first in the country (China Electric Power Enterprise Federation, 2020). In 2020, the UHV company of Southern Power Grid used UAV to inspect the UHV converter station in the Kunming North Converter Station in Yunnan Province and realized the automatic flight inspection of UAV and real-time data management and analysis, which is another milestone of UAV application in China's power grid. In 2021, Longnan power grid of the State Grid began to scale and use UAV to conduct an independent inspection. The intelligence level of autonomous inspection of UAV is standardized comprehensively, and the autonomous cruise modeling and visible light modeling of key lines in the region are completed. The three-dimensional map database of transmission line patrol path is established, and the efficiency of line inspection can be improved by using new technological intelligent equipment. China's UAV inspection technology is more and more mature, diversifying the application.

\section{Current Status of Unmanned Aerial Vehicle Transmission Line Inspection in Other Countries}

Britain. In 1995, Wales University and EA power consulting company developed and tested the robot for transmission line inspection based on the unmanned helicopter of aerobatics (Chen et al., 2011). The UAV was equipped with a high-resolution CCD color visible light camera and a stability control system to enhance its antiwind ability and realize visual tracking and online detection.

Japan. In 2010, the Kansai Electric Power Company and Chiba University jointly developed a set of UAV systems for line inspection (Montambault et al., 2010). The system had a powerful image processing and recognition function, which can automatically identify common faults of transmission equipment, such as broken wire strand, abnormal heating, and welding cracks, and carry out large-scale line corridor inspection, as well as identify the growth of trees near the transmission line and tower.

Spain. In 2000, Campoy and Mejias of Madrid Polytechnic University in Spain were equipped with a visual navigation system in UAV (Mejias et al., 2007). Through machine vision navigation combined with GPS-aided positioning, the automatic navigation function of UAV line inspection was realized. The system included the helicopter airborne subsystem and ground control subsystem. The airborne subsystem gets the real-time image and its pose information. The ground control system analyzes the information returned by the airborne system and provides navigation and control information for UAV.

\section{STANDARDIZATION OF UNMANNED AERIAL VEHICLE TRANSMISSION LINE INSPECTION}

According to GB/T 20000.1:2014 Guidelines for Standardization, standardization is an activity of establishing provisions for common and repeated use regarding actual or potential problems, as well as activity of preparing, issuing, and implementing documents aimed at the achievement of the optimum order in a context and the promotion of common benefit.

The application of standardization in scientific research can avoid repetitive work in research and shorten the design cycle of products. Technical standardization is the most basic technical and competitive requirement for industrial competition in the development of global economic integration and the guarantee to ensure that the industry can be recognized in international competition.

\section{Standardization of China's Unmanned Aerial Vehicle Transmission Line Inspection}

China has formed a relatively complete set of UAV transmission line inspection standardization after many years' development of UAV transmission line inspection. Industry standards have laid a foundation for electric power enterprises to conduct UAV line inspection, and enterprise standard has also supplemented and improved industry standard. These standards, listed in Table $\mathbf{3}$, standardize UAV inspection operation from the aspects of operation safety management, equipment configuration method, functional quality requirements, etc., which improve the operation safety regulations, equipment and technical conditions, and personnel training.

China's standardizations apply to fixed-wing UAV and rotor UAV patrol overhead transmission lines. Through preparing UAV line inspection, the line inspection mode and method are specified and required (China's National Energy Administration, 1482). The UAV line inspection process is shown in Figure 7, and the basic inspection contents are listed in Table 4.

Patrol Mode. It is mainly divided into careful line inspection, channel line inspection, fault line inspection, and special line inspection. The rotary-wing UAV is used in careful line inspection for the first time, such as the line body equipment and ancillary facilities and the lines with defects or abnormalities that need a fine inspection. Fault line inspection and special line inspection are mainly to find and confirm the fault point and check the equipment damage and other abnormal conditions.

Preparation before Line Inspection. The preparation before line inspection includes personnel preparation and operation preparation. The personnel should be qualified to operate UAV and have corresponding health conditions and reasonably allocated according to the line inspection task and the type of aircraft used. Operation preparation is composed of airspace declaration, field investigation, and equipment inspection. Airspace declaration of UAV inspection should be 
TABLE 3 | Standardization of China's UAV transmission line inspection.

\begin{tabular}{|c|c|c|c|}
\hline Approved time & Standard number & Standard name & Standard issuing department \\
\hline \multirow[t]{3}{*}{2015} & DL/T 1482-2015 & Technical guidelines for UAV inspection of overhead transmission lines & National energy administration \\
\hline & Q/GDW 11383-2015 & Configuration guide for UAV inspection system of overhead transmission line & State grid \\
\hline & Q/GDW 11399-2015 & Safety regulations for patrol inspection of electric UAV & \\
\hline 2016 & $\mathrm{DL} / \mathrm{T} 1578-2016$ & Unmanned helicopter inspection system for overhead transmission lines & National energy administration \\
\hline 2018 & T/CEC 193-2018 & Specification for training and assessment of UAV patrol operators in power industry & China Electricity Council \\
\hline
\end{tabular}

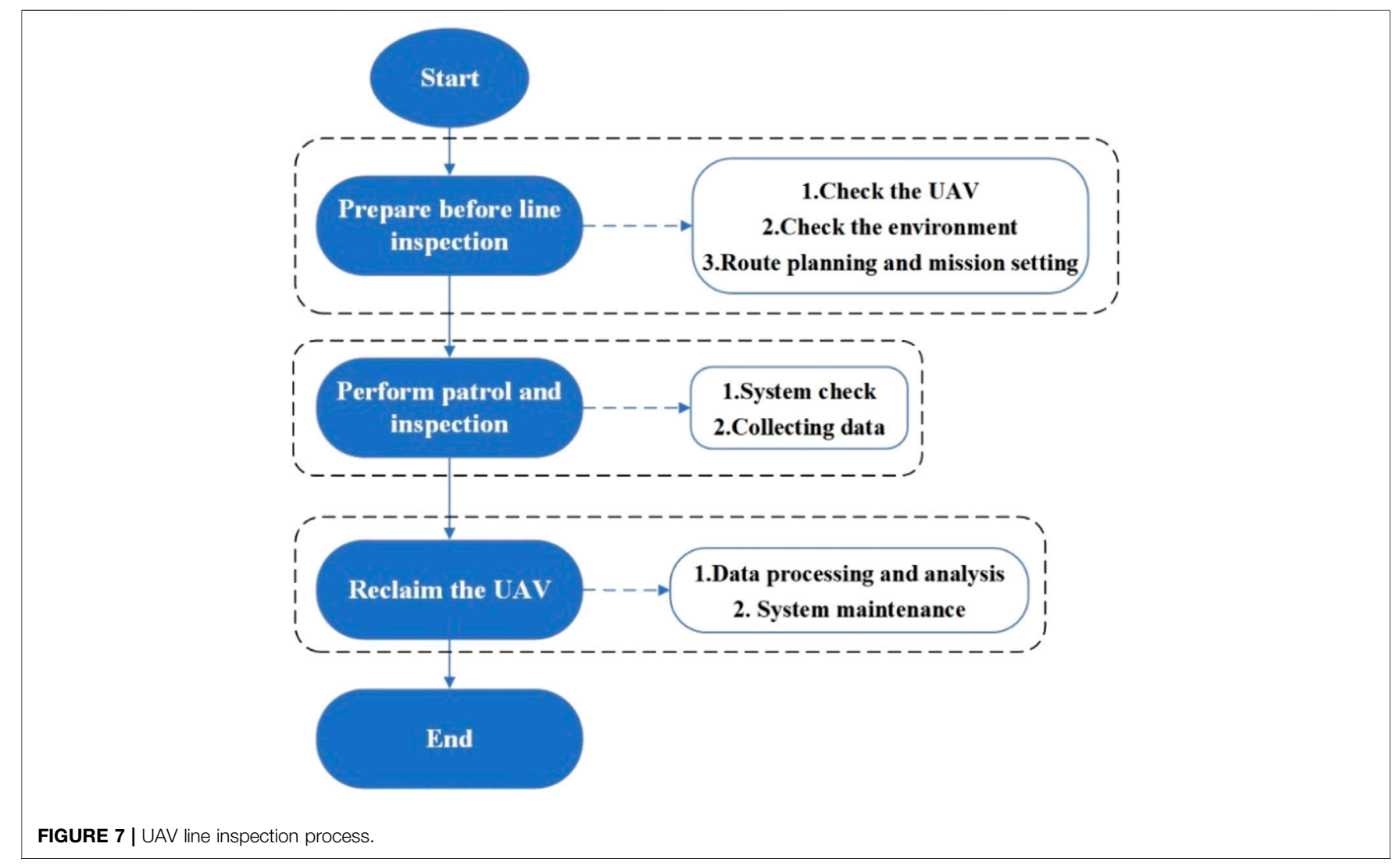

TABLE 4 | Basic inspection contents.

\section{Equipment}

Conducting wire

Drainage line

Clamp

Coiled tubing

Tower

Insulator

Damper

Accessory equipment

Line corridor
Visible light inspection

Infrared inspection

Broken wire, obstacle, broken strand

Broken wire, obstacle, broken strand

Loose

-

Damage, deformation, bolt looseness

Scattered, self-exploding, obstacle

Damage, displacement, defect

Defect

Geological disasters, vegetation growth, external destruction
Hot spot

Hot spot

Contact hot spot

Heating

Thermal breakdown

$-$

$-$

$-$ carried out according to the inspection scope and relevant administrative management measures. Flight inspection requires operators to conduct field investigation in advance to verify the trajectory of the UAV inspection route and surrounding environment and find a suitable place as the take-off and landing point. It is necessary to check the line coordinates and altitude of each tower of the inspection line and whether lines are crossing. The equipment inspection mainly contains the visible light load debugging inspection and infrared temperature measurement load debugging inspection. 
Line Inspection Method. The major methods of line inspection are tower line inspection and intermediate line inspection. Rotary-wing UAV should approach the tower at low speed and hover to collect data when necessary. During patrol inspection, the distance between UAV and line equipment shall not be less than $30 \mathrm{~m}$, the horizontal distance shall not be less than $25 \mathrm{~m}$, and the distance between UAV and surrounding obstacles shall not be less than $50 \mathrm{~m}$. The direction of the line inspection should be parallel to the direction of the ground wire in the corresponding shift. It is not suitable for medium and large UAVs to fly, hover, and cross directly above the line.

\section{Standardization of Other Countries}

To meet the standardization needs of international UAV industry development, the International Organization for Standardization (ISO) established the ISO/TC20/SC16 UAV system standardization subtechnical committee in 2014. The American Society for Testing and Materials (ASTM) has issued 12 civil UAV standards, including eight airworthiness standards, three operational standards, and one training and certification standard. There are three standards for agricultural UAV operators and maintenance in Japan, which specify the safety requirements of UAV design, overhaul, operator qualification, operation, and maintenance (Zeng et al., 2016).

The U.S.A. In 2019, the United States proposed to establish a standardized system of UAV transmission line inspection. Specifically, with energy-related UAV inspections, the American Society of Mechanical Engineers (ASME) is drafting a document of what information need inspectors and UAV owner operators need to know for such missions. The energy industry often adopts a "wait and see" approach when it comes to drones in America. To make inspections of pipelines and transmission lines over long distances practical, flights that are beyond the visual line of sight (BVLOS) are needed. However, there are legal restrictions on the flight range of civil UAVs, so the UAV inspection needs special approval and its standardization process is also more difficult.

Japan. In April 2019, Japan established a research group on UAV line inspection technology and proposed to establish a standardized system of UAV line inspection (Application report of Japan's transmission, 2018). However, the technology of UAV line inspection still stays in the use of visual line inspection but not the radar, infrared, and other technologies. Due to the Japanese UAV laws and regulations, the problem of UAV line inspection in urban areas still needs to be solved. Japan has mature development in the usage of $\mathrm{UAV}$ in agriculture which can share experiences in line inspection standards setting.

European Union. Most EU standards refer to ISO and International Electrotechnical Commission (IEC) standards. Although the application of UAV in transmission line inspection is very extensive, the automatic line inspection of UAV is not mature and a standard system has not been planned yet. Legal regulations restrict the greater use of BVLOS UAVs. BVLOS UAVS need special granted permits for utilities to test.

\section{SWOT-PEST ANALYSIS OF INTERNATIONAL PROMOTION OF CHINA'S UNMANNED AERIAL VEHICLE TRANSMISSION LINE INSPECTION STANDARDIZATION}

SWOT analysis is a systematic and logical approach to investigate the internal and external factors of the studied subject, upon which the most suitable promotion mode under the current situation can be determined via the comprehensive analysis of related factors of the investigation subject. Meanwhile, PEST analysis refers to the specific and detailed analysis of the macroenvironment. This study combines SWOT and PEST to study the feasibility of international promotion of China's UAV transmission line inspection standardization.

\section{Strengths}

\section{Political}

In 2018, the standardization administration of China announced the "Belt and Road" (B\&R) action plan (2018-2020 years) which further defined "promoting the internationalization of China's standards and promoting international cooperation in production and equipment manufacturing,". Moreover, through the standards information platform established by the Belt and Road (B\&R) initiative, some of China's standards have been widely promoted around the world. Since the line inspection technology of B\&R countries is not as advanced as that of China and the standard has not been formed yet, China can use its accumulated experience in this field to provide them with more services. Meanwhile, the standardization is a consequential technical basis and rule for economic and trade exchanges and industrial cooperation in promoting the $\mathrm{B} \& \mathrm{R}$ construction process (Shao et al., 2020).

\section{Economical}

Located in the east of Asia, China covers 9,600,000 square kilometers, with a population of 1.437 billion and GDP of 15.67 trillion US dollars in $2020(\mathrm{Hu}, 2021)$. At present, China has become the world's second-largest economy, the largest industrial, commodity trading, and foreign exchange reserve country. Unlike other economies, China has maintained economic growth despite COVID-19, and its GDP is projected to grow by $8.4 \%$ in 2021 , according to the International Monetary Fund. The booming economy provides opportunities for the technology development and promotion of the standardization of UAV transmission line inspection.

\section{Social}

With the commercialization of civil UAV, people have a deeper understanding of UAV and a higher degree of acceptance. At the same time, UAV application reduces the risk and cost of line inspection, providing more options for power companies and creating new jobs. $5 \mathrm{G}$ technology and the application of artificial intelligence will further improve the efficiency of line inspection. China's line inspection UAV has more functions and more 
reliable technology, and the key is low price and high-cost performance. These advantages add a greater attraction to the promotion of China's UAV line inspection standard.

\section{Technological}

China owns a variety of key technologies of UAV inspection and has rich experience in operation. In 2013, China Southern Power Grid Company (CSG) began to promote the mechanical patrol operation of transmission lines and established the mechanical patrol operation center in 2015. Focused on the development of power UAV application capability, this operation center issued the standard system and carried out the key technology research work.

At present, lidar technology and RTK technology are the main means of UAV autonomous inspection (DUAN, 2016). Using CW lidar, CSG realized the measurement of safe distance between the conductor and ground. With the help of Internet of Things technology, the State Grid Corporation of China and CSG upload UAV inspection data to the data cloud in real time and use the deep neural network algorithm, big data, and image recognition technology to automatically analyze inspection data and accurately find defects and generate inspection report. In the UAV line inspection, the defect intelligent recognition technology is adopted. Through the UAV inspection image intelligent recognition algorithm, the manual interpretation of inspection images is gradually reduced or even replaced, so as to realize the practicability of artificial intelligent recognition technology (Cui, 2016). These key technologies in inspection lay the foundation for the popularization of China's UAV inspection standards.

\section{Weaknesses Political}

China lacks an effective platform for the application and promotion of standards abroad, and the communication channels among the government, industry, and enterprises are limited. For the internationalization achievements of key technical fields and helpful standards, there is insufficient cooperation and exchange between governments. Meanwhile, European and American standards are still dominant in many fields, so China's standards encounter great difficulties in the promotion and application.

\section{Economical}

COVID-19 has led to a global recession and severely hampered international economic cooperation, and most of the cooperation projects between China and other countries are blocked. Under the global environment of economic downturn, China's exported products may face high import taxes, which is not conducive to the promotion of China's UAV inspection standards.

\section{Social}

UAV application in transmission lines includes equipment maintenance and technical personnel training. UAV may encounter various technical obstacles and damages in the process of inspection. Simple faults may be solved on site, but for some complex problems of UAVs, they can only be returned to the manufacturer for maintenance, which increases the maintenance cost of line inspection UAVs. Furthermore, since the training of line inspection UAV operators is not common in the world, for countries with less-developed technology, the cost of training UAV operators will increase. This will hinder the promotion of China's UAV line inspection standards.

\section{Technological}

It is difficult to break through the technical level of UAV line inspection. Although China's enterprises have abundant funds and numerous technical personnel teams, the development of UAV is still facing a strong technical bottleneck, endurance and weather resistance, which greatly limits the application of civil UAV (Liu et al., 2019b). Besides, there are professional UAV line inspection operation training institutions in China, such as the UTC training center in DJI, which can provide training and issue flight certificates for UAV line inspection operators. However, the number of operators who meet the UAV flight qualification is still very limited, and a large number of UAV operators need to be trained to realize UAV line inspection widely.

\section{Opportunities Political}

The B\&R initiative has been promoted by the Chinese government, and foreign cooperation between the relevant enterprises was benefited from it. At the same time, China continues to improve the national innovation system, speed up the construction of a powerful country in science and technology, and strongly support the development of UAV and other new technologies.

\section{Economical}

In the 14th five-year plan (2021-2025), China clearly points out that it is necessary to improve the overseas production service network and circulation system, accelerate the international development of producer services such as finance, consulting, accounting, and law, and promote the going out of China's products, services, technology, brands, and standards. The Chinese government will improve the integrated regulatory system for domestic and foreign trade and promote the convergence of laws and regulations, regulatory system, business qualifications, quality standards, inspection and quarantine, certification, and accreditation. These measures provide a good business environment for China's economy in the future. Meanwhile, the international economy will usher in a great recovery with the increasing coverage of COVID-19 vaccine, which has laid an economic foundation for the international promotion of China's UAV line inspection standardization.

\section{Social}

Language is an important factor for the international promotion of Chinese UAV line inspection standards. At present, some translators do not understand UAV line inspection technology while the operators and engineers are not proficient in foreign languages. The shortage of professional translators may lead to the problems of incorrect or inconsistent expression of technological 
terms. Translation should be faithful to the original, not only to meet the requirements of grammar and correct expression of content but also to reflect the professionalism and standardization, so as to avoid multiple foreign expressions in the same Chinese professional vocabulary, ambiguity, and misunderstanding (Chen and Zhang, 2020).

\section{Technological}

China's artificial intelligence development has achieved a desirable technical goal, and 5G network construction has basically reached the annual goal. With the steady development of these two technologies, artificial intelligence will further enhance the intelligent interaction, information processing, analysis, and decision-making capabilities of UAVs, while $5 \mathrm{G}$ will improve the communication and data transmission capabilities of UAVs. The two will jointly release more potential power in the international promotion of China's UAV line inspection standard.

\section{Threats}

\section{Political}

For developing countries or less-developed countries and regions, their national standards are missing or not perfect. For example, the technical indicators of most central Asian countries still follow the standards of the former Soviet Union from the 1960s to the 1970s (Ma and Ma, 2018). The lack of a top-level strategy, planning of related promotion work, professional promotion personnel, and institutions, especially the lack of systematic, mature, and effective application, creates challenges for the local application of China's UAV line inspection standard.

\section{Economical}

Since 2018, trade frictions between China and the United States have escalated to many fields such as trade, science and technology, finance, and international rules, which has led to a dramatic impact on the global economy. Although vaccination has brought hope to stimulate economic activity and expand investment, the continuous economic stimulus policies around the world, especially the unprecedented scale of the US stimulus plan, have also triggered concerns about economic overheating and rising inflation expectations.

\section{Social}

The projects invested in many countries are generally required to follow European or American standards, and the acceptance of China's standards is not very often. Usually, the standards of these projects have been clearly implemented in bidding documents. At the same time, it may be restricted by law in some countries, and the promotion of China's UAV line inspection standard may need to make corresponding changes.

\section{Technological}

The system of standards is distinctive in different countries. Relevant technical standards in the United States are prepared and adopted voluntarily by industry organizations, institutions, and enterprises according to the technical regulations issued by the government. EU standards which are formulated by government agencies are part of the regulations, and most of them are mandatory. China's technical regulations and standards are governed by the state and are divided into four levels: national standards, industry standards, local standards, and enterprise standards. At present, China implements a standard system that combines mandatory standards with recommended standards (Chen, 2021).

Information security and personal privacy are also problems of UAV line inspection applications. It is inevitable for UAV from taking photos of buildings and roads when it conducts the line inspection, which may involve personal privacy, especially in urban areas. Moreover, how to ensure the security of information and data collected during the analysis is also a crucial issue that should be paid attention to.

\section{CONCLUSIONS AND EXPECTATIONS}

Nowadays, UAV has gradually become the main tool of transmission line inspection. Meanwhile, the standardization of such industry further accelerates the promotion of line inspection technology. Based on the analysis of the promotion of UAV line inspection via the SWOT analysis method, the following conclusions can be summarized:

(a) China's civil UAV technology is at the leading level in the world, which has abundant experience and advanced technologies. Thus, China's UAV line inspection standard can be used as a reference standard for other countries, which can help them to promote such industry in a more reliable and fast way.

(b) China's UAV line inspection standards may be limited by laws and regulations in other countries, and the acceptance of Chinese standards in other countries is also relatively low. Therefore, China's standards can be correspondingly changed according to the actual situation of other countries, and China's UAV line inspection technology can also act as an important driving force for promotion.

(c) China is the main member of the Belt and Road Initiative and the global destiny community, which needs to take the responsibility to promote China's technology around the world. In this context, the promotion of China's UAV line inspection standard will be strongly supported, which will contribute to the development and popularization of international UAV line inspection technology.

The existing standards of UAV inspection enable electric power companies to use UAVs for routine patrol tasks, but for the future development and application of patrol technology, there still exists a lot of room for UAVs to exploit for more advancement. With the development of UAV technology, the merits of UAV such as high economy, strong flexibility, and not restricted by terrain make it a hot research topic in transmission line inspection. There are some prospects for future development of UAV inspection. 
Autonomous inspection: Manually manipulated UAV inspection is extremely complicated and difficult for the flyer, and there is a great demand to develop an intelligent UAV for autonomous inspection. The inspection results of different manual operation modes may vary greatly, and the inspection of overhead transmission lines is mostly cyclic and repetitive work. Relying on the operators completely will cause the problems of high labor intensity and low inspection efficiency, which will make it difficult to adapt to the new needs of power operation and maintenance. Therefore, autonomous inspection has become one of the research directions.

Battery life improvement: On the other hand, the lack of UAV range is a bottleneck problem that limits the promotion of the mounted UAV power patrol mode, and the current stage of application in the field of power inspection of small- and medium-sized multirotor UAVs in the patrol grid technology inspection load after the endurance of the patrol to maintain 10-30 min inspectors need to frequently replace the battery, which seriously affects the efficiency of inspection. In the future, it is also possible to improve the endurance of UAVs by using nest power supply.

Auxiliary maintenance: UAV can carry out not only defect monitoring but also simple maintenance operations. In the field of UAV auxiliary maintenance, we need to actively explore new technologies, including developing live water flushing, emergency lighting, and equipment anomaly detection based on voiceprint recognition, in order to further expand the application of UAV in inspection.

The last is the maintenance of UAV. In the aspect of UAV maintenance, the maintenance manual is formulated for the whole cycle process of UAV inspection, and the routine

\section{REFERENCES}

Application report of Japan's transmission (2018). Application Report of Japan's Transmission Line Inspection UAV. Available at: https://www.meti.go.jp/meti_ lib/report/H30FY/000078.pdf.

Chen, C., Chen, B. M., and Lee, T. H. (2011). Special Issue on Development of Autonomous Unmanned Aerial Vehicles. Mechatronics 21, 763-764. doi:10.1016/j.mechatronics.2011.03.009

Chen, D., Geng, J., Zhang, W., and Guo, L. (2020). Dynamic Modeling and Simulation of Flapping wing UAV. Computer Meas. Control 28 (06), 202-206.

Chen, J., and Zhang, B. (2020). Research on Overseas Application and Promotion Mode of Chinese Standards. China standardization 1, 57-61.

Chen, L. (2021). One Dimensional " B\&R " Background Standardization and Modern Circulation Industry Development. Business Econ. Res. 1, 18-21.

China Electric Power Enterprise Federation (2020). Annual Development Report 2020 of China Electric Power Industry, 6.

China's National Energy Administration Technical Guidelines for UAV Inspection of Overhead Transmission Lines, China: Beijing. DL/T 1482-2015.

Cui, M. (2016). Parameter Test and Radiation Calibration of Solar Blind Ultraviolet Image Intensifier and ICCD. Graduate School of Chinese Academy of Sciences.

Duan, M. (2016). 3D Power Lines Reconstruction from Airborne LiDAR point Cloud. Acta Geodaetica et Cartographica Sinica 45 (12), 1495.

Fei, L. (2019). Research on the Development Status of Stratospheric Airship. Decis. making exploration 05, 96.

Fu, J., Shao, G., and Wu, L. (2017). Defect Detection of Line Facility Using Hierarchical Model with Learning Algorithm. High Voltage Eng. 43 (1), 266-275.

Gangolu, S., and Sarangi, S. (2020). A Novel Complex Current Ratio-Based Technique for Transmission Line protection. Prot. Control. Mod. Power Syst. 5 (3), 239-247. doi:10.1186/s41601-020-00168-6 maintenance and research work on key components of UAV is carried out. Therefore, in addition to the UAV transmission line inspection standards, it is also necessary to formulate corresponding standards for UAV maintenance.

\section{DATA AVAILABILITY STATEMENT}

The original contributions presented in the study are included in the article/Supplementary Material; further inquiries can be directed to the corresponding author.

\section{AUTHOR CONTRIBUTIONS}

$\mathrm{XL}$ : conceptualization and writing-reviewing and editing. ZL: writing-original draft preparation and investigation. HW: writing-reviewing and editing. WL: conceptualization, resources, and supervision.

\section{ACKNOWLEDGMENTS}

We appreciatively acknowledge the support of the program entrusted by the legislative Affairs Commission of the Standing Committee of the Yunnan Provincial People's Congress (648820140054) and the Talents Training Program of Kunming University of Science and Technology (KKZ3201524007).

Geospatial Media and Communications (2018). Rotary-wing UAV. Available at: https://www.geospatialworld.net/news/dji-announces-drone-law-enforcementpartnership-with-axon.

Guo, H., he, W., and Sun, Y. (2017). "Development prospect and Prospect of Parafoil UAV," in Proceedings of the third China Aviation Science and technology conference.

Hassanalian, M., and Abdelkefi, A. (2017). Classifications, Applications, and Design Challenges of Drones: A Review. Prog. Aerospace Sci. 91, 99-131. doi:10.1016/j.paerosci.2017.04.003

He, J., Chen, K., Meng, L., Luo, Y., Liang, C., and Xu, Y. (2020). Review of protection and Fault Handling for a Flexible DC Grid. Prot. Control. Mod. Power Syst. 5 (2), 151-165. doi:10.1186/s41601-020-00157-9

$\mathrm{Hu}$, A. (2021). The Year of Building a Moderately Prosperous Society in an AllRound Way in 2020 (An Evaluation of China's Economic and Social Development). J. Beijing Univ. Technology, 1-20.

Hu, M., Liu, W., Lu, J., Fu, R., Peng, K., Ma, X., et al. (2018). On the Joint Design of Routing and Scheduling for Vehicle-Assisted Multi-UAV Inspection. Future Generation Computer Syst. 94, 214-223.

Icao's circularUAS (2011). ICAO's Circular UAS. Available at: https://www.icao. int/Meetings/UAS/Documents/Circular\%20328_en.pdf.

Kumar, A., Anwar, M. N., and Kumar, S. (2021). Sliding Mode Controller Design for Frequency Regulation in an Interconnected Power System. Prot. Control. Mod. Power Syst. 6 (1), 77-88. doi:10.1186/s41601-021-00183-1

Kumar Injeti, S., and Kumar Thunuguntla, V. (2020). Optimal Integration of DGs into Radial Distribution Network in the Presence of Plug-In Electric Vehicles to Minimize Daily Active Power Losses and to Improve the Voltage Profile of the System Using Bioinspired Optimization Algorithms. Prot. Control. Mod. Power Syst. 5 (1), 21-35. doi:10.1186/s41601-019-0149-x

Lanny Lin (2021). Parafoil UAV. Available at: http://lannyland.blogspot.com/ 2009/05/robot-of-day-cq-10-snowgoose-cargo.html. 
Liang, W., Wu, D., and Gu, S. (2020). Route Optimization Method for fine Autonomous Inspection of Transmission Line Multi Rotor UAV. High voltage Technol. (9).

Liu, Z., DU, Y., and Chen, Y. (2019a). Simulation and experiment on the Safety Distance of Typical $\pm 500 \mathrm{kV}$ DC Transmission Lines and Towers for UAV Inspection. High Voltage Eng. 45 (2), 426-432.

Liu, Z., Wang, X., and Liu, Y. (2019b). Application of Unmanned Aerial Vehicle Hangar in Transmission Tower Inspection Considering the Risk Probabilities of Steel Towers. IEEE Access.

Ma, P., and Ma, J. (2018). Overview and Analysis of Standardization Development in Tajikistan. Stand. Sci. 9, 14-16.

Manual transmission line Inspection (2018). News Feature: Power Line Inspector under High Temperature. Available at: https://www.sohu.com/a/244982732_99923877.

Mejias, L., Correa, J. F., Mondragon, I., and Campoy, P. (2007). COLIBRI: A Vision-Guided UAV for Surveillance and Visual Inspection. Proc. 2007 IEEE Int. Conf. Robotics Automation. doi:10.1109/robot.2007.363883

Miao, X., Liu, Z., and Yan, Q. (2020). Overview of UAV Transmission Line Intelligent Inspection Technology. J. Fuzhou Univ. Nat. Sci. Edition (2), 198-209.

Montambault, S., Beaudry, J., Toussaint, K., and Pouliot, N. (2010). "On the Application of VTOL UAVs to the Inspection of Power Utility Assets," in 2010 1st International Conference on Applied Robotics for the Power Industry. doi:10.1109/carpi.2010.5624443

Muniappan, M. (2021). A Comprehensive Review of DC Fault protection Methods in HVDC Transmission Systems. Prot. Control. Mod. Power Syst. 6 (1), 1-20. doi:10.1186/s41601-020-00173-9

Padhy, S., and Panda, S. (2021). Application of a Simplified Grey Wolf Optimization Technique for Adaptive Fuzzy PID Controller Design for Frequency Regulation of a Distributed Power Generation System. Prot. Control. Mod. Power Syst. 6 (1), 21-36. doi:10.1186/s41601-021-00180-4

Peng, X., Qian, J., and Mai, X. (2016). Automatic Power Line Inspection Technology of Large Unmanned Helicopter and its Application. South. Power Syst. Technology 10 (2), 24-31.

Qian, J., Mai, X., and Wang, K. (2016). Application and Effect of Large Scale Patrol Inspection for Power Lines of Large Unmanned Helicopter in Guangdong Power Grid. Guangdong electric power 29 (005), 124-129.

Shao, G., Liu, Z., Fu, J., Tan, J., Yi, C., and Zhou, L. (2020). Research Progress of UAV Inspection Technology for Overhead Transmission Lines. High voltage Technol. 46 (01), 14-22.

Singhal, G., Bansod, B., and Mathew, L. (2018). Unmanned Aerial Vehicle Classification, Applications and Challenges: A Review. Basel, Switzerland: Preprints.
Sui, Y., and Ning, F. (2021). Review of Power Inspection Technology of UAV Mounted on Overhead Transmission Line. Power grid Technol. 1-15.

Tang, L., Yu, L., and Zhang, Y. (2018). Research and Application of Civil UAV System. Machine tool and hydraulic 46 (05), 127-133.

Tang, L., Yu, L., and Zhang, Y. (2018). Research and Application of Civil UAV System. Machine tools and hydraulics.

Tavakoli, M., and Nafar, M. (2020). Human Reliability Analysis in Maintenance Team of Power Transmission System protection. Prot. Control. Mod. Power Syst. 5 (4), 270-282. doi:10.1186/s41601-020-00176-6

Tzu-ti, H. (2020). Flapping-wing UAV. Taiwan News. 2020/07/23. https://www. taiwannews.com.tw/en/news/3972498.

Uav transmission line Inspection (2020). Professional UAV System Manufacturer AOPA Training Institutions. http://www.ttaviation.com.

Unmanned airship (2014). Russia Purchased from Belarus an Unmanned Airship "BAK EM". Available at: https://en.topwar.ru/61036-rossiya-priobrela-ubelorussii-bespilotnyy-dirizhabl-bak-em.html.

Volt Aerial Robotics (2016). Fixed-wing UAV. Available at: https://www. voltaerialrobotics.com/wavesight.

Yi, W., Liming, C., Lingyu, K., Jie, Z., and Miao, W. (2017). "Research on Application Mode of Large Fixed-wing UAV System on Overhead Transmission Line," in 2017 IEEE International Conference on Unmanned Systems (ICUS) in Beijing, 88-91.

Zeng, Q., Chen, G., and Yang, G. (2016). "UAV Standardization Research and Application Promotion," in Standardization helps supply side structural reform and Innovation: Proceedings of the 13th China Standardization Forum.

Zhai, Y., Zhao, H., Zhao, M., and Jiao, S. (2018). Design of Electric Patrol UAVs Based on a Dual Antenna System. Energies 11, 866. doi:10.3390/en11040866

Zhao, T., Pan, X., and He, Q. (2017). "Application of Dynamic Ant colony Algorithm in Route Planning for UAV," in Seventh International Conference on Information Science and Technology of IEEE, 433-437.

Conflict of Interest: The authors declare that the research was conducted in the absence of any commercial or financial relationships that could be construed as a potential conflict of interest.

Copyright (c) $2021 \mathrm{Li}, \mathrm{Li}$, Wang and Li. This is an open-access article distributed under the terms of the Creative Commons Attribution License (CC BY). The use, distribution or reproduction in other forums is permitted, provided the original author(s) and the copyright owner(s) are credited and that the original publication in this journal is cited, in accordance with accepted academic practice. No use, distribution or reproduction is permitted which does not comply with these terms. 